\title{
Arquitetura no Brasil: ensino e profissão
}

Architecture in Brazil: Teaching and practice

\author{
Elena Salvatori \\ Doutora em Teoria e História da Arquitetura - UPC \\ elena.salvatori@ufrgs.br \\ Faculdade de Arquitetura - UFRGS
}

\begin{abstract}
Resumo
O estabelecimento, a localização e a disseminação dos cursos de Arquitetura e a constituição do campo profissional no Brasil estão relacionados, historicamente, às demandas institucionais e aos projetos modernizadores dos governos, ao fenômeno da urbanização e à ampliação dos segmentos populacionais médios, principalmente depois da Segunda Guerra. O fenômeno apresenta algumas peculiaridades, no caso do Rio Grande do Sul, que o colocam em primeiro lugar na proporcionalidade de escolas de Arquitetura e de arquitetos no conjunto dos Estados brasileiros. O número de arquitetos já formados conheceu dois períodos de grande incremento, coincidentes com dois momentos distintos na implantação de novas escolas encontrando-se o segundo em pleno desenvolvimento. Indaga-se sobre a adequação entre este número e a realidade do mercado de trabalho, demonstrando-se que a série histórica dos novos registros junto ao CREA-RS, longe de dirimir dúvidas, indica novos caminhos para investigações sobre as relações entre formação e prática profissional.
\end{abstract}

Palavras-chave: ensino de arquitetura, formação e prática profissional da arquitetura, campo da arquitetura no Brasil.

\begin{abstract}
The establishment, location and dissemination of Architecture courses and professional field constitution in Brazil are historically related to the institutional demands and the modernizing governmental projects, the urbanization phenomenon and the growth of middle class, especially after Second World War. This phenomenon presents some peculiarities in Rio Grande do Sul State, placed first in proportion of Architecture Schools and Architects among Brazilian states. The number of graduated architects has experienced two periods of great increase, simultaneously with two different introduction moments of new schools, being the second one in current development. The adjustment between this number and the reality of the market demand is inquired, showing that the historical series of new registrations within CREA-RS, far from settling doubts, indicates new investigation paths about the relations between graduation and professional practice.
\end{abstract}

Keywords: architecture teaching, graduation and professional practice of architecture, architecture field in Brazil.

\section{História e contexto}

O estabelecimento do ensino de Arquitetura no Brasil é, relativamente, recente. O Curso de Arquitetura da Academia Imperial de Belas Artes do Rio de Janeiro, que fora o único do Brasil por mais de cinqüenta anos, era uma instituição pública que recebia estudantes de origem modesta desde sua criação, em 1826. Havia, então, a necessidade de implantar equipamentos e instituições que apoiassem o desenvolvimento do Reino Unido do Brasil, recém criado pela instalação da corte portuguesa no País em 1808 . Iniciou-se o ensino 
oficial de artes e ofícios industriais, principalmente depois da acolhida da chamada "Missão Francesa", em 1816.

O ensino da Academia Imperial de Belas Artes do Rio de Janeiro modernizou-se com a criação de novas e especializadas disciplinas, em 1854, sob a direção de Manoel de Araújo Porto Alegre (1806-1879), o Barão de Santo Ângelo. Foram criadas a figura do professor catedrático e uma estrutura de ensino que se manteve inalterada até 1959, ano em que a instituição foi extinta já como Escola Nacional de Belas Artes - ENBA, nome que Ihe foi dado pelo Estado Republicano em 1889. Durante todo o século XIX, essa Academia/Escola formou um número reduzido de arquitetos, mas, a partir de princípios do século $\mathrm{XX}$, começou a receber estudantes provenientes de estratos sociais mais cultos, atraídos pelas oportunidades que o desenvolvimento econômico proporcionava. Um sintoma da mudança das condições do mercado de trabalho foi a criação de diversos cursos de Arquitetura em novas escolas de Engenharia ou Belas Artes, nas principais cidades do país, a partir do final do século XIX. A história dessas etapas iniciais foi recuperada e extensamente comentada por Barreto (1983), Fiore (1992), e, ainda, Passaglia (1991).

A recente presença da Arquitetura erudita no Brasil tampouco conheceu longos períodos de estabilidade, pois o século $X X$ foi pródigo em mudanças estruturais que afetaram todos os âmbitos da vida mundial. Tais mudanças se aceleraram na segunda metade do século, quando se ampliaram as possibilidades de comunicação e intercâmbio global. Podem-se identificar algumas etapas e alguns fatos que influenciaram o desenvolvimento local da Arquitetura, mas este será melhor entendido como um processo, fenômeno capaz de sobrepor diferentes realidades, às vezes contraditórias, no mesmo momento cronológico - como concluiu Segawa (1999). A história da profissão no Brasil está relacionada tanto com a evolução do pensamento arquitetônico e à mudança da visão filosófica do mundo, como com o crescimento das populações urbanas, o surgimento de novas classes sociais e à progressiva globalização da economia. Também se relaciona com a mudança do paradigma político que, no caso brasileiro, passou da República ao Estado Nacional Estadista nos anos 1930 e, deste, ao Estado Mínimo nos anos 1990, orientação que refletiu em todas as instituições sociais. Entre as décadas de 1930 e 1980, diversos governos de diferentes orientações promoveram a realização de obras emblemáticas que utilizaram as formas da Arquitetura Moderna como símbolo do progresso do país. Outros autores também ressaltam a coincidência entre a constituição da autonomia do campo da Arquitetura no Brasil e a construção da hegemonia do Movimento Moderno que, em certos momentos, se confundem, motivo pelo qual perduraria a influência local daquele ideário até entrado o último quartel do século $X X$.

\section{A constituição do campo profissional}

Do terço final do século XIX à Primeira Guerra Mundial, o Brasil experimentou o que se chamou a "Ilustração Brasileira", época marcada pelo cientificismo e o universalismo. Acreditava-se, então, que o caminho para o progresso era único para todos os povos: assim era necessário somente que se acelerasse o passo para alcançar-se um lugar ao lado dos países mais desenvolvidos do mundo ocidental - pensamento que esteve na raiz das primeiras tentativas de organização da Universidade brasileira, de acordo com Orso (2001). A proclamação da República, em 1889, parecia ser o meio privilegiado para as mudanças, mas a I Guerra marcou o retorno a certo romantismo nacionalista, ao entendimento de que era necessário desenvolver o 
patriotismo, organizar a defesa da soberania e criar instituições que garantissem a ampliação da democracia. Uma questão que se impôs de forma crescente foi a busca de uma identidade nacional, gerando a discussão que se estendeu ao campo da Arquitetura, da Literatura e das Artes e que produziu a histórica exposição de Arte Moderna de 1922.

A estrutura política da chamada Primeira República estava fundada nas oligarquias rurais, principalmente nos empresários cafeeiros paulistas, que foram à falência com a quebra da Bolsa de Nova York, em 1929. No ano seguinte, uma revolução colocou Getúlio Vargas (1882-1954) na presidência do país, com objetivo de criar, rapidamente, uma nova ordem social e econômica. De perspectiva modernizante, buscava o desenvolvimento nacional autônomo, liderado por um governo forte que, em 1937, implantou um regime ditatorial no Brasil, o chamado Estado Novo, e acelerou suas intervenções. Suas realizações foram tão bem recebidas, que o ditador voltaria, em 1951, como presidente eleito por voto direto da população.

A partir do Estado Novo, começou uma etapa muito favorável à expansão do campo profissional, não só pelas obras efetivamente demandadas pelo Estado, mas pelo efetivo progresso econômico, industrial e urbano que foram incrementados, mais tarde, pelos excedentes das exportações obtidos durante a II Guerra. A existência de condições favoráveis ao desenvolvimento entre 1930 e 1960 . Este último, o ano em que Brasília foi inaugurada pelo presidente Juscelino Kubitschek (1902-1976), levou a uma exaltação do discurso sobre a importância social da Arquitetura, capaz de expressar a nova imagem do país, que passava da sociedade agroexportadora para a urbano-industrial. Segundo o que defende Barreto (1983), mais que uma simples adesão dos arquitetos brasileiros aos projetos das classes sociais dominantes, havia uma complementaridade entre o objetivo de afirmação profissional e a demanda desenvolvimentista. Como conseqüência da intensa colaboração entre campo profissional e educativo, da aceitação social da Arquitetura Moderna, dos movimentos de renovação estética em curso, "tudo indicava um grande salto de qualidade no processo de desenvolvimento da arquitetura brasileira", de acordo com Graeff (1995, p. 46).

Os antecedentes imediatos justificavam o otimismo: o mundo do II Pós-Guerra experimentou a chamada "Idade de Ouro" do capitalismo e da social-democracia, em que os objetivos foram o desenvolvimento, a igualdade e o pleno emprego; os Estados Unidos empreenderam uma série de ações de apoio aos aliados do bloco ocidental que beneficiaram o Brasil, incrementando sua indústria de base, a produção de bens de consumo e o comércio internacional. De acordo com diversos autores, como Fatherstone (1995), Ianni (1971), Barreto (1983), Segawa (1999) e Durand (1989), surgiram as condições para a ampliação e criação de segmentos populacionais bem remunerados, que ampliaram as classes sociais médias e modificaram a estrutura de consumo, processo que se intensificou nas décadas de 1960 e 1970 . Um fenômeno simultâneo foi o aumento da participação popular no sistema democrático, rompendo a hegemonia dos grupos políticos tradicionais e, no caso brasileiro, aumentando a pressão por reformas estruturais que distribuíssem melhor os resultados do desenvolvimento. Em plena "Guerra Fria", porém, forças políticas conservadoras temeram que as "Reformas de Base" do programa do Presidente João Goulart (1918-1976), que sucedera Juscelino Kubitschek, abrissem espaço ao comunismo e, em 1964, instauraram uma ditadura militar que controlaria o país por vinte anos. 
$\mathrm{Na}$ categoria dos arquitetos, houve um desconcerto temporal, pois alguns de seus mais influentes personagens, como Oscar Niemeyer (n. 1907), Edgar Graeff (1921-1990), Demétrio Ribeiro (1916-2003) e Vilanova Artigas (1915-1985), foram imediatamente afastados das escolas de Arquitetura e tiveram seus direitos políticos cassados. Os arquitetos modernos, ainda que patrocinados pelos poderes instituídos, eram então identificados com as esquerdas políticas, fato que tem origem no discurso humanista-liberal de princípios do século XX, considerado "subversivo" pelo Governo militar. Alguns arquitetos eram, na realidade, filiados ao Partido Comunista brasileiro, mas, ainda de acordo com Barreto (1983), essa identificação provém da repercussão das experiências comunistas nos Congressos Internacionais de Arquitetura Moderna (CIAM), principalmente na área da habitação social mínima e projetos para massas populacionais. Paradoxalmente, algumas das propostas geradas pelo Urbanismo Moderno foram apropriadas pelos governos militares brasileiros e implementadas com a plena colaboração da classe profissional dos arquitetos.

O período da ditadura militar esteve carregado de contradições não somente para a Arquitetura, mas para toda a sociedade brasileira. Instituiu-se o serviço de censura aos meios de comunicação e editoras, as viagens ao exterior foram dificultadas e se estabeleceu uma rede de informantes a serviço do Departamento de Ordem Pública e Social, presentes, inclusive, nas salas das universidades. Aos poucos, foram fechando as revistas nacionais especializadas em Arquitetura, enquanto a importação de livros e outros bens era dificultada. O ensino experimentou, talvez, seu pior período; alguns segmentos sociais vivenciaram a perseguição e o exílio, mas as oportunidades profissionais se ampliavam de uma forma jamais vista.

Logo em seguida ao golpe militar, foi instituído o Banco Nacional da Habitação - BNH, em 1964, e o Serviço Federal de Habitação e Urbanismo (SERFAU), em 1966. O primeiro ativou imediatamente a economia, permitiu o investimento no mercado da construção, a criação de empregos e promoveu socialmente segmentos mais desfavorecidos. O segundo, mais significativo do ponto de vista estratégico, elaborou os Planos Nacionais de Desenvolvimento (PNDs), grande referência dos governos militares no Brasil.

Os dois primeiros PNDs, de 1972-1974 e 1974-1979, respectivamente, inseriram os arquitetos de uma maneira inédita, não só nos diversos âmbitos e níveis administrativos, mas na efetiva implantação dos grandiosos projetos de infra-estrutura, responsáveis por novas oportunidades profissionais no campo urbanístico. O desenvolvimento econômico foi acelerado, com grande afluxo de capital externo e substituição de importações, o que ampliou as classes médias urbanas e, circularmente, suas demandas por habitação, equipamentos e serviços. Por outro lado, a idéia de um Estado forte e centralizador, base da doutrina militar, retardou a implementação das idéias neoliberais que evoluíam nos demais países ocidentais. Ou seja, se apresentaram as condições contextuais para que os arquitetos pudessem exercer o papel social propugnado por teóricos do Movimento Moderno. Muitos arquitetos, destituídos de cargos públicos por motivos políticos, voltaram ao mercado de trabalho por meio da contratação para elaboração de projetos, pois sua experiência era fundamental para dar as rápidas respostas que o contexto desenvolvimentista demandava, nessa época conhecida como a do "Milagre Brasileiro".

A partir de meados dos anos 1970, com a ruptura do pacto de Breton Woods e as crises do petróleo que a seguiram, reduziu-se o ritmo de crescimento dos países ocidentais e, no Brasil, os investimentos na 
implantação dos PNDs não foram plenamente efetuados. O fracasso de todos os planos de recuperação econômica que acompanharam os primeiros anos da democratização do país, desde meados dos anos 80 , produziu um novo paradoxo, desta vez entre novos níveis de exigências estabelecidos no campo da formação de arquitetos e as condições objetivas da prática profissional. A massificação da formação, a aceitação das idéias neoliberais e a transformação do mercado da construção em mais uma commodity - em que a rápida remuneração é mais importante que a qualidade arquitetônica -, intensificaram a competição e a dissolução dos vínculos corporativos entre os profissionais.

A representatividade profissional também se fragmentou, sinal da crescente complexidade do mercado de trabalho e da heterogeneidade social dos arquitetos. Tendo em vista o crescimento do número de arquitetos empregados, principalmente no sistema de planejamento estatal, o Instituto de Arquitetos do Brasil (IAB, 1921) fomentou a criação de Sindicatos regionais, a partir de 1974. Por outro lado, as contradições internas à categoria se acentuaram: os arquitetos empresários decidiram separar-se do IAB, formando a Associação Brasileira de Escritórios de Arquitetura (AsBEA, 1973), com representações regionais. Mais tarde, surgiu a Associação Brasileira de Arquitetos Paisagistas (ABAP, 1976) e, em Porto Alegre, a Associação de Arquitetos de Interiores (AAI, 1987).

Depois de 1978, ano da Lei da Anistia Política, reapareceram as publicações especializadas de arquitetura e se retomaram os intercâmbios com o campo internacional, ensaiando-se as primeiras revisões dos postulados modernos, principalmente no centro e no sul do País, mais afastados do foco das escolas carioca e paulista, que se mantinham como fortes influências. Mas, para Segawa (1999), o debate pós-moderno não foi capaz de explicar, por si só, os rumos que a arquitetura brasileira tomou desde então. Fatos como a interiorização da economia e das escolas de Arquitetura trouxeram maior diversidade ao campo e à emergência de regionalismos, com arquiteturas desvinculadas dos modelos anteriores. O mesmo autor observa que, nos grandes centros, abrandou-se a busca de uma identidade nacional para a arquitetura; a arquitetura mais visível atendia a padrões de eficiência tecnológica e imagem empresarial, muitas vezes definidos em âmbito internacional, exigência dos grupos multinacionais que se instalavam no país. $O$ panorama dos anos 80 se completava com o trabalho de alguns arquitetos ainda das primeiras gerações modernas, que continuavam ativos e fiéis à suas origens.

No ano de 1993, se organizou uma exposição conjunta de Arquitetura de Brasil e Argentina, que deu origem à Bienal de Buenos Aires. Para Segawa (1999), esta exposição significou o início de uma nova crítica no Brasil, preocupada com a dimensão disciplinar da Arquitetura e desvinculada da retórica política das décadas anteriores. Na década de 1990, embora a crença no papel transformador da Arquitetura tenha diminuído, se assistiu, ainda, ao incremento da historiografia arquitetônica e à redescoberta da Arquitetura Moderna brasileira. Dois prêmios internacionais foram conferidos a arquitetos brasileiros em 2000, o Mies van Der Rohe (a Paulo Mendes da Rocha, n. 1928) e o Verônica Green (a Jorge Mário Jáuregui, n. 1948). A longevidade e produtividade dos arquitetos (e engenheiros) modernos da primeira geração, da etapa "heróica" da Arquitetura Moderna no Brasil - Lúcio Costa (1902-1998), Burle Marx (1909-1994), Lina Bo Bardi (1901-1992), Carmen Portinho (1903-2001), Sérgio Bernardes (1919-2002) - e do próprio Oscar Niemeyer (n. 1907) contribuem também para a manutenção da lenda perante as novas gerações. 
O final do século XX esteve marcado pela ambigüidade; o desenvolvimento da crítica e o incremento das relações com o campo profissional internacional se caracterizaram pelos mesmos revivalismos e idéias neoconservadoras sobre o meio ambiente e o patrimônio arquitetônico, característicos dos tempos pósmodernos. O Estado, mecenas histórico da Arquitetura no Brasil, deixou de promover obras grandiosas e abdicou de investir no bem-estar social. A arquitetura mais evidente foi a promovida pelo mercado imobiliário, que se apropriou das formas arquitetônicas mais surpreendentes com finalidades publicitárias, segundo a crítica de Guerra (2001). Para Segawa (1999), embora haja novos experimentos no campo, ainda não se definiram tendências que pudessem substituir a Arquitetura Moderna como o principal fator identitário para os arquitetos brasileiros.

\section{Escolas e arquitetos no Brasil}

De acordo com a Associação Brasileira de Ensino de Arquitetura - ABEA (2003) -, em 1933, ano da primeira regulamentação profissional no Brasil, existiam quatro escolas de Arquitetura no país. Além dos cursos da ENBA do Rio de Janeiro, da Escola Politécnica e da Escola de Engenharia do Mackenzie de São Paulo, havia uma Faculdade independente, a da Universidade de Minas Gerais, criada em 1930. Fiore (1992) menciona, também, a existência de outros dois antigos cursos, da Escola de Belas Artes e da Escola Politécnica da Bahia, fundadas em 1877 e 1896, respectivamente. Ao que tudo indica, esses cursos estavam inoperantes em 1933, como é também o caso do antigo curso de Arquitetura da Escola de Engenharia de Porto Alegre, que funcionou entre 1898 e 1911. Segundo a mesma ABEA, as escolas já eram doze, em 1966; vinte e oito, em 1974; setenta e duas, em 1994 e cento e quarenta e sete, em 2002. Em 2008, são contabilizadas cento e oitenta e quatro escolas de Arquitetura. Os períodos de crescimento mais significativos ocorreram entre 1966 e 1974 e entre 1994 e 2002, de 16,66\% e 13,02\% ao ano, respectivamente.

Mas, se a tendência dos anos 1970 e 1980 foi de multiplicar as escolas nas regiões mais desenvolvidas do país, Sudeste e Sul, na década de 1990 foi a de dispersão geográfica, na busca de regiões afastadas desses tradicionais centros culturais e econômicos. Ou seja, o primeiro período de expansão do ensino corresponderia ao incremento da economia brasileira e a uma efetiva demanda por profissões técnicas; o segundo, à ampliação do mercado da educação, proporcionado pela prescrição de regras facilitadoras para a criação de novos cursos por instituições privadas de ensino. Em 2008, não há escolas apenas em quatro dos vinte e sete estados brasileiros. O fenômeno do aumento de escolas de Arquitetura foi observado, igualmente, no mundo ocidental, como uma tendência geral do ensino universitário nas décadas de 1980 e 1990, de acordo com Monedero (2003). A distribuição geográfica dessas escolas brasileiras pode ser observada na Figura 1: 


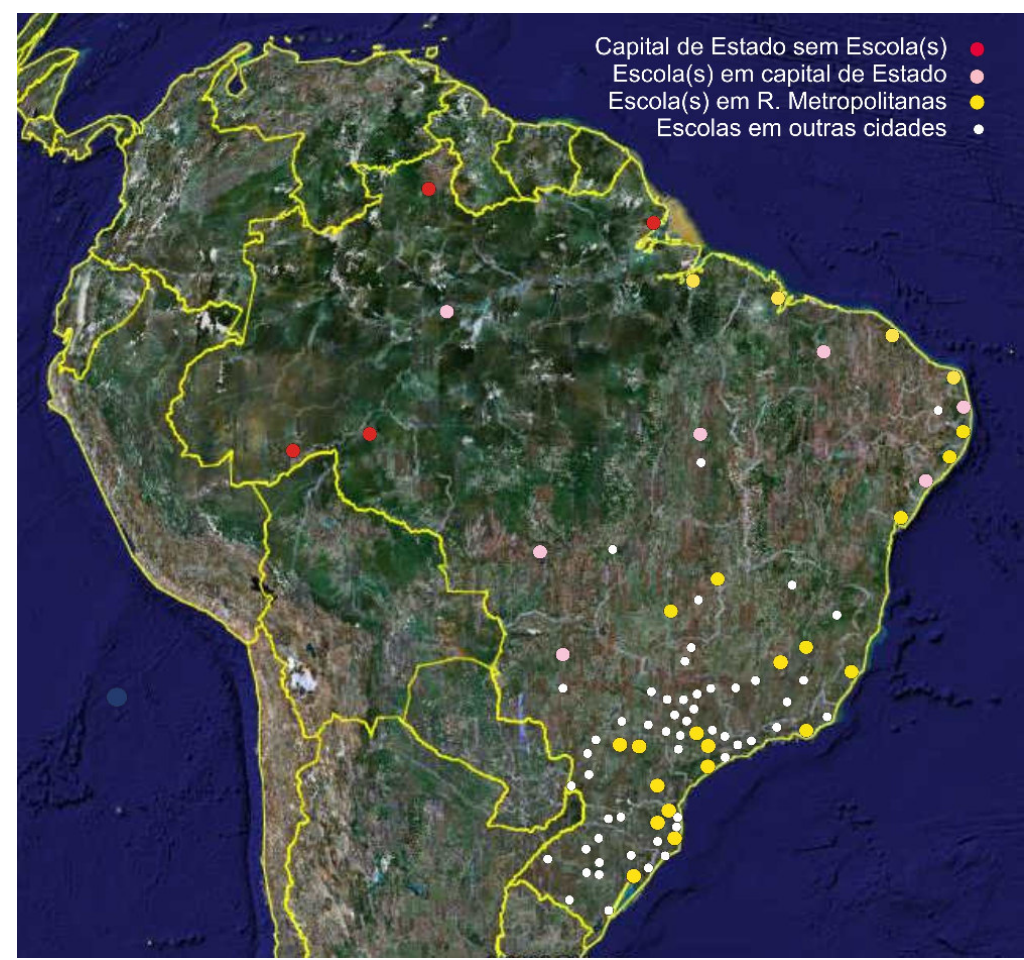

Figura 1. Escolas de arquitetura no Brasil, dispersão territorial - 2008.

Nas estatísticas apresentadas pela União Internacional de Arquitetos (UIA), em 2002, (in Monedero, 2003), que estimava a presença de oitenta mil arquitetos no Brasil em 2002, o país apresentava uma média de 0,463 arquitetos para cada mil habitantes, ocupando posição equivalente à de países como Holanda ou França (com índices de 0,472 e 0,455, respectivamente). O estudo da UIA - que não incluiu países com índices menores que 0,200 - apresenta as posições mais destacadas para Japão e Itália (2,292 e 1,449 arq./1.000 hab, respectivamente). A proporção de profissionais existentes em cada um dos quarenta e cinco países pesquisados está diretamente relacionada às condições locais de formação e o exercício, principalmente, à regulamentação profissional e ao controle da oferta de novas vagas nas escolas. Também influi nesse fato a existência ou não de profissões que venham a competir com o arquiteto no mercado de trabalho, como é o caso da Engenharia Civil, no Brasil, modalidade profissional desconhecida em outros países.

As estatísticas atuais referentes ao número de escolas e, ainda, de arquitetos registrados nos Conselhos Regionais de Engenharia, Arquitetura e Agronomia (CREA), de cada Estado, são apresentadas na Tabela 1, abaixo, que as relaciona com outros indicadores. Deve-se considerar, porém, como provisórios os dados do Conselho Federal de Engenharia, Arquitetura e Agronomia (CONFEA), referentes ao número de arquitetos registrados por Estado em abril de 2008, uma vez que foram detectadas inconsistências entre esses e os dados informados diretamente por alguns Conselhos Regionais. Esse fato foi levado ao conhecimento do CONFEA, que iniciou, em agosto deste mesmo ano, uma verificação geral dos dados do recadastramento profissional realizado em 2007. 
Tabela 1. Arquitetos e escolas no Brasil - por estado e região, população e território, 2007.

\begin{tabular}{|c|c|c|c|c|c|c|c|c|c|c|c|}
\hline 일 & Estado & $\begin{array}{l}\text { População } \\
\text { estimada }\end{array}$ & $\begin{array}{l}\% \text { sobre } \\
\text { população } \\
\text { total }\end{array}$ & $\begin{array}{l}\% \text { média } \\
\text { crescimento } \\
\text { anual } \\
1991-2000\end{array}$ & $\begin{array}{r}\text { Densidade } \\
\text { hab } / \mathrm{km}^{2}\end{array}$ & \begin{tabular}{|l|l} 
& $\%$ \\
população & em área \\
embanizada
\end{tabular} & Escolas & $\begin{array}{l}\text { Escolas / } 1 \\
\text { milhão hab }\end{array}$ & \begin{tabular}{|l} 
Arquitetos \\
no Sistema \\
CREA- \\
CONFEA
\end{tabular} & $\begin{array}{l}\text { Arquitetos } \\
\text { /1.000 hab }\end{array}$ & $\begin{array}{l}\text { Arquitetos } \\
\% \text { sobre } \\
\text { total }\end{array}$ \\
\hline
\end{tabular}

\begin{tabular}{|c|c|c|c|c|c|c|c|c|c|c|c|}
\hline \multirow{7}{*}{$\begin{array}{l}\text { 㟧 } \\
\text { 을 }\end{array}$} & RONDÔNIA & 1.453 .756 & 0,81 & 2,22 & 5,80 & 61,80 & 0 & 0 & 57 & 0,039 & \\
\hline & \begin{tabular}{|l|} 
ACRE \\
\end{tabular} & 655.385 & 0,33 & 3,28 & 3,65 & 66,40 & 0 & 0 & 32 & 0,048 & \\
\hline & \begin{tabular}{|l} 
AMAZONAS \\
\end{tabular} & 3.221 .939 & 1,66 & 3,32 & 1,79 & 74,61 & 4 & 1,241 & 463 & 0,143 & \\
\hline & RORAIMA & 395.725 & 0,19 & 4,57 & 1,45 & 76,11 & 0 & 0 & 15 & 0,037 & \\
\hline & PARÁ & 7.065 .573 & 3,65 & 2,54 & 4,96 & 65,73 & 2 & 0,283 & 1.351 & 0,191 & \\
\hline & AMAPÁ & 587.311 & 0,28 & 5,74 & 3,33 & 89,01 & 0 & 0 & 102 & 0,173 & \\
\hline & TOCANTINS & 1.243 .627 & 0,68 & 2,59 & 4,17 & 73,50 & 2 & 1,608 & 193 & 0,155 & \\
\hline ST & Área $3.853 .327,229 \mathrm{~km} 2$ & 14.623 .316 & 7,6 & 2,86 & 3,79 & 69,83 & 8 & 0,547 & 2.213 & 0,151 & 2,97 \\
\hline
\end{tabular}

\begin{tabular}{|c|c|c|c|c|c|c|c|c|c|c|c|}
\hline \multirow{9}{*}{ 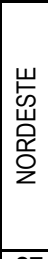 } & MARANHÃO & 6.118 .995 & 3,33 & 1,53 & 17,00 & 59,42 & 2 & 0,326 & 381 & 0,062 & \\
\hline & \begin{tabular}{|l|} 
PIAUÍ \\
\end{tabular} & 3.032 .421 & 1,68 & 1,08 & 11,31 & 62,90 & 2 & 0,663 & 250 & 0,082 & \\
\hline & \begin{tabular}{|l|} 
CEARÁ \\
\end{tabular} & 8.185 .286 & 4,37 & 1,73 & 50,91 & 70,38 & 2 & 0,244 & 814 & 0,099 & \\
\hline & \begin{tabular}{|l} 
RIO GRANDE DO NORTE \\
\end{tabular} & 3.013 .740 & 1,63 & 1,55 & 52,22 & 72,65 & 2 & 0,663 & 1.112 & 0,368 & \\
\hline & PARAIBA & 3.641 .395 & 2,03 & 0,81 & 61,05 & 70,85 & 3 & 0,823 & 697 & 0,191 & \\
\hline & PERNAMBUCO & 8.485 .386 & 4,67 & 1,18 & 80,30 & 75,56 & 4 & 0,471 & 1.840 & 0,216 & \\
\hline & ALAGOAS & 3.037 .103 & 1,66 & 1,29 & 101,34 & 66,83 & 2 & 0,658 & 805 & 0,265 & \\
\hline & SERGIPE & 1.939 .426 & 1,05 & 2,01 & 81,13 & 69,16 & 1 & 0,515 & 337 & 0,146 & \\
\hline & BAHIA & 14.080 .654 & 7,71 & 1,09 & 23,16 & 66,07 & 3 & 0,213 & 2.064 & 0,143 & \\
\hline $\begin{array}{l}\text { ST } \\
\end{array}$ & Área 1.554.257,004 km2 & 51.534 .406 & 28,13 & 1,30 & 33,15 & 69,04 & 21 & $\mathbf{0 , 4 0 7}$ & 8.300 & 0,161 & 11,17 \\
\hline
\end{tabular}

\begin{tabular}{|c|c|c|c|c|c|c|c|c|c|c|c|}
\hline ш & \begin{tabular}{|l|} 
MINAS GERAIS \\
\end{tabular} & 19.273 .506 & 10,54 & 1,43 & 30,46 & 80,67 & 16 & 0,830 & 5.376 & 0,278 & \\
\hline 5 & ESPIRITO SANTOS & 3.351 .669 & 1,82 & 1,97 & 67,20 & 78,38 & 4 & 1,193 & 934 & 0,278 & \\
\hline 岁 & RIO DE JANEIRO & 15.420 .375 & 8,47 & 1,30 & 328,03 & 95,29 & 13 & 0,843 & 12.771 & 0,828 & \\
\hline क & SÃO PAULO & 39.827 .570 & 21,80 & 1,78 & 148,96 & 91,51 & 60 & 1,506 & 23.868 & 0,599 & \\
\hline ST & Área $924.511,292 \mathrm{~km} 2$ & 77.873 .120 & 42,63 & 1,60 & 84,23 & 90,52 & 93 & $\overline{1,194}$ & 42.949 & 0,551 & 57,74 \\
\hline
\end{tabular}
Região Sudeste - Renda mensal per capita: $\mathrm{R} \$ 935,90 ;$ Escolaridade: 7,2 anos de estudo

\begin{tabular}{|c|c|c|c|c|c|c|c|c|c|c|c|}
\hline \multirow{3}{*}{5} & PARANÁ & 10.284 .503 & 5,64 & 1,39 & 47,96 & 79,83 & 15 & 1,458 & 4.939 & 0,488 & \\
\hline & SANTA CATARINA & 5.866 .252 & 3,15 & 1,85 & 56,14 & 75,17 & 11 & 1,875 & 2.893 & 0,493 & \\
\hline & RIO GRANDE DO SUL & 10.582 .840 & 6,00 & 1,22 & 36,14 & 79,53 & 20 & 1,889 & 8.107 & 0,766 & \\
\hline & Área $576.409,569 \mathrm{~km} 2$ & 26.733.595 & 14,79 & 1,42 & 46,38 & 80,94 & 46 & 1,720 & 15.939 & 0,596 & 21,43 \\
\hline
\end{tabular}
Região Sul - Renda mensal per capita: $R \$ 901,40 ;$ Escolaridade: 6,9 anos de estudo

\begin{tabular}{|c|c|c|c|c|c|c|c|c|c|c|c|}
\hline & MATO GROSSO DO SUL & 2.265 .274 & 1,22 & 1,73 & 5,81 & 82,47 & 3 & 1,324 & 1.046 & 0,461 & \\
\hline 岂 & MATO GROSSO & 2.854 .642 & 1,48 & 2,39 & 2,77 & 77,43 & 3 & 1,050 & 670 & 0,234 & \\
\hline (1) & GOIÁS & 5.647 .035 & 2,95 & 2,47 & 14,69 & 86,38 & 4 & 0,708 & 1.434 & 0,253 & \\
\hline 峲 & DISTRITO FEDERAL & 2.455 .903 & 1,20 & 2,77 & 352,16 & 93,08 & 6 & 2,443 & 1.823 & 0,742 & \\
\hline ST & Área 1.606.371,505 km2 & 13.222 .854 & 6,85 & $\mathbf{2 , 3 7}$ & 8,23 & 86,73 & 16 & 1,210 & 4.973 & 0,376 & 6,69 \\
\hline
\end{tabular}

Região Centro-Oeste - Renda mensal per capita: $\mathrm{R} \$ 931,70$; Escolaridade: 6,7 anos de estudo

\begin{tabular}{|c|c|c|c|c|c|c|c|c|c|c|c|}
\hline 푱 & $\begin{array}{c}\text { BRASIL - 8.514.876,599 } \\
\mathrm{km}^{2}\end{array}$ & 183.987.291 & 100,00 & 1,63 & 21,60 & 81,23 & 184 & 1,000 & 74.374 & 0,404 & 100,00 \\
\hline
\end{tabular}

Fontes: Sistema CONFEA-CREA, Censos Demográficos IBGE, ABEA, Escolas de Arquitetura: Renda e Escolaridade: PNAD 2006*.

* Renda mensal per capita = média do total dos rendimentos mensais de maiores de 10 anos; Escolaridade = média de anos de estudo para pessoas de 25 anos e mais.

De acordo com a Tabela 1, ressalvada a observação referente à necessidade de aguardar a conferência dos dados do recenseamento profissional promovido pelo sistema CREA-CONFEA, em 2007, constata-se a proporcionalidade média atual de 0,404 arq/1.000 hab., no caso do Brasil. Confirma-se, também, a existência de uma escola de Arquitetura para cada milhão de habitantes. Mas, ao mesmo tempo, podem-se observar as grandes diferenças existentes entre as regiões brasileiras, também no que concerne à distribuição de escolas e à presença proporcional de arquitetos, que poderão ser relacionados, por sua vez, a outros indicadores, como o de escolaridade e renda.

A região Norte acumula alguns recordes negativos nos quesitos densidade populacional, número de escolas de Arquitetura e de arquitetos e, ainda, na proporção entre esses e o total da população em que apresenta os indicadores mais baixos. A população total só não é menor que a do Centro-Oeste, acontecendo o mesmo fato com os indicadores de população urbana e de escolas, rendimento médio e escolaridade, somente mais altos que os da região Nordeste. Apesar disso, e embora a taxa média geométrica de crescimento anual venha declinando no Brasil de modo geral, desde a década de 1970, o maior crescimento ocorre nas regiões 
Norte e Centro-Oeste. Essa seria a contribuição das frentes de expansão retardatária da fronteira e do entorno de Brasília, segundo o IBGE (2001), situação que aponta para uma dinâmica populacional que deverá alterar substancialmente a fisionomia da região dentro de poucos anos.

A região Nordeste, tradicionalmente, apresenta pouco crescimento; fica sempre abaixo das médias nacionais. No último Censo, mostrou o mais significativo declínio na taxa de crescimento demográfico registrado recentemente no Brasil, fruto da redução da fecundidade e das já históricas perdas migratórias. Ao revelar muitas áreas de estagnação econômica, também aparece com os mais baixos indicadores de renda e escolaridade e a menor taxa de população urbana.

O Sudeste concentrou, sistematicamente, e em todos os recenseamentos havidos, o maior contingente populacional e absorveu 41,98\% do crescimento total do país entre 1991 e 2000, mais que a década anterior. Concentra também a maior parte dos arquitetos brasileiros $(57,74 \%)$ e cerca da metade das escolas de Arquitetura (50,54\%). Pode-se relacionar sua atratividade à qualidade de vida gerada pelo grau de urbanização, o mais alto do Brasil (90,52\% da população em área urbana), e ao maior nível de escolaridade e rendimentos. Fica, porém, em segundo lugar relativamente à proporcionalidade de escolas e arquitetos, cujo melhor índice está na região Sul.

A região Sul, a menor em termos de território, também apresenta uma baixa taxa de crescimento demográfico, ligeiramente maior que o do Nordeste, mas vem mantendo uma posição estabilizada na composição populacional relativa, desde a década de 1950. O grau de escolaridade é o segundo melhor do país, somente abaixo do Sudeste; e a renda da região quase se equipara à do Centro-Oeste, ao qual cedeu a segunda posição na Pesquisa Nacional por Amostra de Domicílios - PNAD 2006. A região apresenta o maior índice proporcional de arquitetos e de escolas do país, com 0,596 arq/1.000 hab e 1,720 esc/1 milhão hab, para os quais o Rio Grande do Sul (RS), por sua vez, contribui com os maiores valores absolutos e relativos.

A região Centro-Oeste aparece como uma nova frente de expansão no território brasileiro, em termos demográficos e econômicos. Apesar de ter a menor população, apresenta a segunda posição geral nos quesitos: rendimentos médios per capita, taxa de crescimento anual, grau de urbanização e, ainda, proporcionalidade de escolas de Arquitetura. O grau de escolaridade praticamente se equipara ao do Sul, que mantém a segunda posição geral. Mas é necessário dizer que as tendências somam a contribuição do Distrito Federal, área de grande atratividade e de indicadores individuais significativos, como o mais alto grau de urbanização do país (93,08\%), a maior densidade (352,16 hab/ha), o maior índice proporcional de arquitetos da região, com 0,742 arq/1.000 hab e a mais alta relação escolas-habitantes do país, de 2,443 esc/1 milhão hab.

\section{Escolas e arquitetos no Rio Grande do Sul}

A implantação do ensino de Arquitetura no Estado do Rio Grande do Sul deu-se somente em 1945, acompanhando a tendência histórica de ocupação e urbanização tardias em relação ao Nordeste e ao Sudeste brasileiros. Até então, a Arquitetura era realizada por arquitetos de outras regiões e estrangeiros, principalmente alemães, que construíram uma importante obra local. No entanto, vivia-se um vazio 
ocasionado pela regulamentação profissional de 1933, que reservava a atividade a portadores de diplomas nacionais. A iniciativa de organização do primeiro curso, porém, foi conseqüência das recomendações do Primeiro Congresso Nacional de Arquitetos, de 1944, para que se instalassem novos e independentes cursos por todo o país. Repercutia nacionalmente a publicação do catálogo da exposição Brazil Builds, realizada em Nova York, em 1943, e os arquitetos brasileiros propugnavam por uma identidade profissional própria.

Inicialmente, criaram-se dois cursos independentes em Porto Alegre; um ligado ao Instituto de Belas Artes e, em seguida, outro, ligado à Escola de Engenharia da Universidade do Rio Grande do Sul, que formaram suas primeiras turmas em 1949. Logo em 1952, como resultado da federalização da Universidade, que reuniu cursos superiores independentes do Estado, ambos os cursos foram fundidos para resultar na Faculdade de Arquitetura da UFRGS.

Durante quase vinte anos, a Faculdade de Arquitetura da UFRGS foi a única a formar arquitetos no estado. Em 1971, implantou-se uma segunda escola, na Universidade do Rio dos Sinos - UNISINOS, na região metropolitana de Porto Alegre - RMPA. Até 1976, surgiram outras, duas delas ainda na RMPA (Universidade Luterana do Brasil - ULBRA, em Canoas e Centro Universitário Ritter dos Reis UNIRITTER, em Porto Alegre) e uma terceira, em Pelotas (Universidade Federal de Pelotas - UFPEL), importante pólo econômico da região sul do Estado.

A partir de 1990, iniciou-se um novo ciclo de crescimento, que acrescentou, até 2006, mais quinze escolas às cinco existentes em 1976. Inicialmente, criaram-se quatro escolas em outras cidades-pólo do Estado (Universidade da Região da Campanha - URCAMP, em Bagé; Universidade Católica de Pelotas - UCPEL; Universidade Federal de Santa Maria - UFSM, e Universidade de Passo Fundo - UPF). Depois de 1996, ano da promulgação da nova Lei de Diretrizes e Bases da Educação, que dispensou a aprovação prévia de novos cursos superiores criados por universidades privadas, acelerou-se o ritmo desse crescimento. Só naquele ano foram abertos três novos cursos (Universidade de Caxias do Sul - UCS; Pontifícia Universidade Católica do Rio Grande do Sul - PUCRS, em Porto Alegre e Universidade de Cruz Alta - UNICRUZ). Em 1998, surgiram mais dois cursos de Arquitetura (ULBRA - Torres e Universidade de Santa Cruz do Sul - UNISC) e, de 2000 a 2006, praticamente um curso novo foi inaugurado a cada ano (Centro Universitário FEEVALE, em Novo Hamburgo; Universidade Regional Integrada do Alto Uruguai e das Missões - URI, no Campus Santiago; ULBRA - Santa Maria; Centro Universtário Franciscano - UNIFRA, também em Santa Maria; Centro Universitário UNIVATES em Lageado e Centro Universitário Metodista do IPA, em Porto Alegre). Até agosto de 2008, contabilizaram-se vinte Cursos de Arquitetura em todo o estado, dos quais quatro ainda não haviam encerrado um ciclo inteiro de formação e, portanto, não contribuíram para a totalização de egressos.

Os cursos de Arquitetura do RS estão distribuídos da seguinte forma: sete na região metropolitana de Porto Alegre, quatro na capital; nove em cidades que são centros regionais, com destaque para Santa Maria (três cursos) e Pelotas (dois cursos); e quatro em outras cidades do interior do estado. A localização geográfica preferente está na metade norte do Estado, mais populosa, urbanizada e industrializada, como pode ser visualizada na Figura 2: 


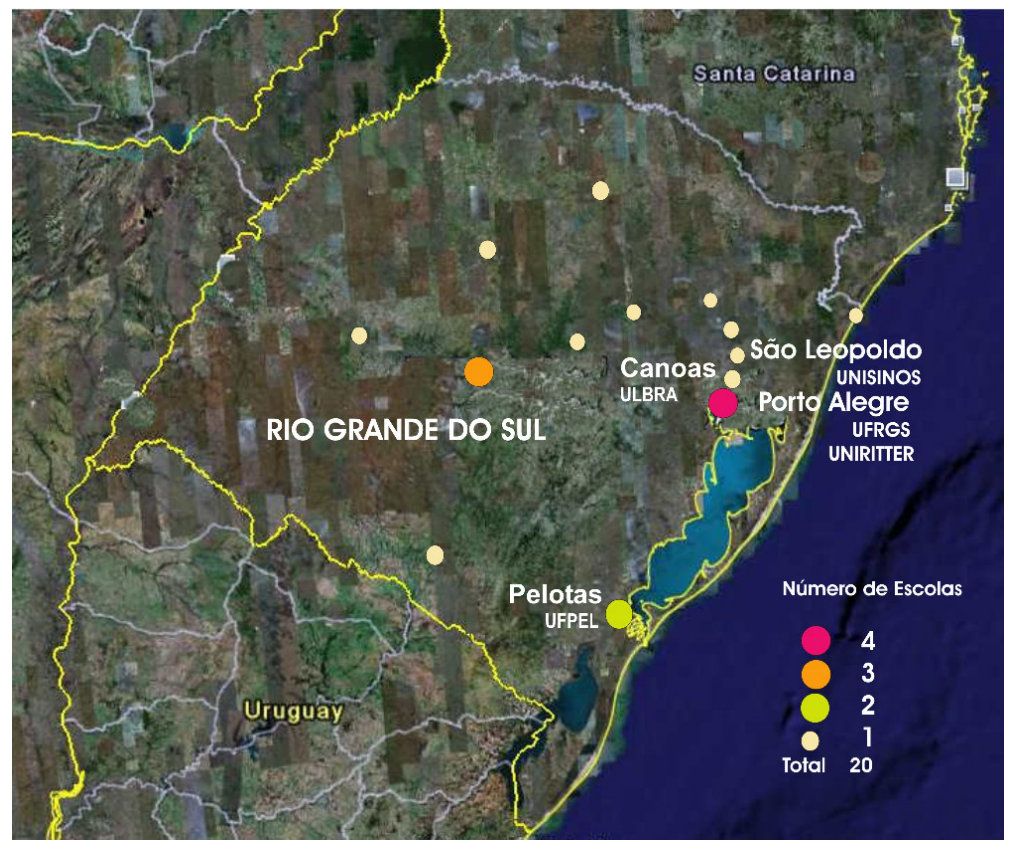

Figura 2. Escolas de arquitetura no RS, dispersão territorial - 2008.

No Rio Grande do Sul, verificaram-se tendências de crescimento e dispersão de escolas de Arquitetura similares ao comportamento em âmbito nacional. Um primeiro ciclo de crescimento ocorreu na década de 1970, coincidente com o aumento da demanda por profissões técnicas no período de implementação dos Planos Nacionais de Desenvolvimento - PND I e II e de ativação geral da economia, que localizou escolas na capital e na região metropolitana e, ainda, em cidade-pólo regional. Um outro ciclo se iniciou no início da década de 1990, que distribuiu as novas escolas junto aos novos mercados educacionais, preferentemente em centros regionais das áreas mais urbanizadas e populosas do estado. A partir da nova LDB, de 1996, que admitiu também o estabelecimento de Centros de Ensino Superior exclusivamente dedicados ao ensino, ou seja, sem a obrigação de promover a pesquisa, houve, ainda, uma diversificação institucional, que favoreceu sua instalação em cidades de pequeno e médio porte. Esse fenômeno, segundo Ristoff e Giolo (2006), representa uma nova etapa de busca de equanimidade nas oportunidades de formação superior que, no Rio Grande do Sul, ainda estaria bastante restrita aos estratos populacionais mais favorecidos. A figura 3, que segue, demonstra a relação entre o incremento de escolas e o crescimento do número de diplomados em todo o estado. 


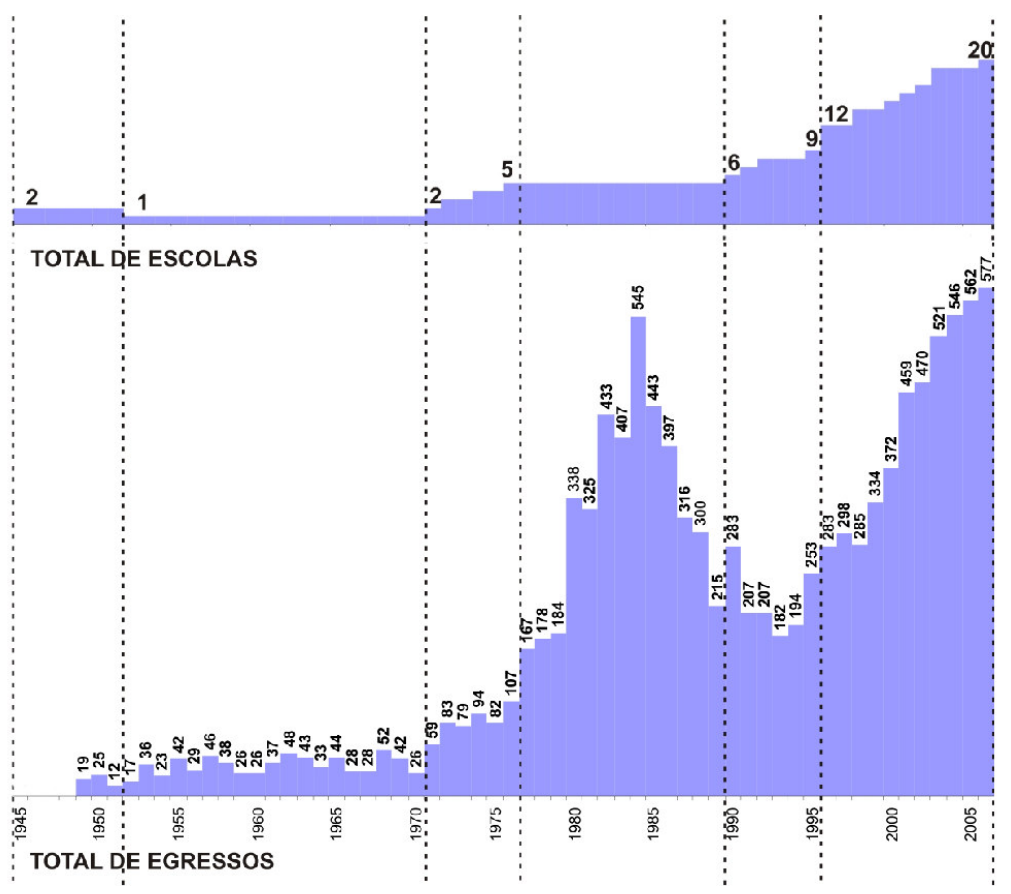

Figura 3. Escolas do RS, incremento x total de egressos, 1945-2006.

Desde sua criação, em 1952, e até 1975, período em que foi a única a diplomar arquitetos no estado, a Faculdade de Arquitetura da UFRGS formou 1.061 arquitetos, ao ritmo de 34,9 anuais até 1970. De 1971 a 1975, por efeito da Reforma Universitária, que ampliou as vagas nas Universidades públicas, a Faculdade de Arquitetura da UFRGS diplomou 79,4 alunos ao ano.

Entre 1976 e 1994, período de dezoito anos, as cinco escolas em atividade no estado foram responsáveis pela formação de um grande número de arquitetos, cerca de 5.428, perfazendo uma média de 295,6 diplomados ao ano; ou seja, diplomaram $47,20 \%$ do total histórico de 11.505 , considerando o conjunto de todas as escolas desde 1949. O número atingiu um máximo em 1984, com 545 alunos diplomados, e foi declinando até chegar a 240, em 1993, provavelmente um reflexo tardio da desaceleração do crescimento e das crises econômicas da segunda metade da década de 1980. Observa-se que, nos anos 1990, foi revertida a tendência, aumentando-se gradativamente o número anual de diplomados.

Nos onze anos transcorridos entre 1995 a 2006 - em que o número de escolas passou de oito para vinte -, diplomaram-se 4.960 arquitetos, ou cerca de $43,11 \%$ do total histórico. As onze escolas criadas a partir de 1990 já respondem por cerca de $10 \%$ desse total, e um pouco mais da metade é contribuição exclusiva de três, UCPEL, UCS e PUCRS.

Em 2004, computando-se 546 egressos no conjunto de dezesseis escolas gaúchas, seria superada a marca histórica de 1984, e, desde então, o número anual de formados vem crescendo ligeiramente. As Tabelas 2 e 3 mostram a contribuição anual de cada uma das escolas gaúchas. 
Tabela 2. Escolas de arquitetura RS, total anual de egressos, 1949-2006.

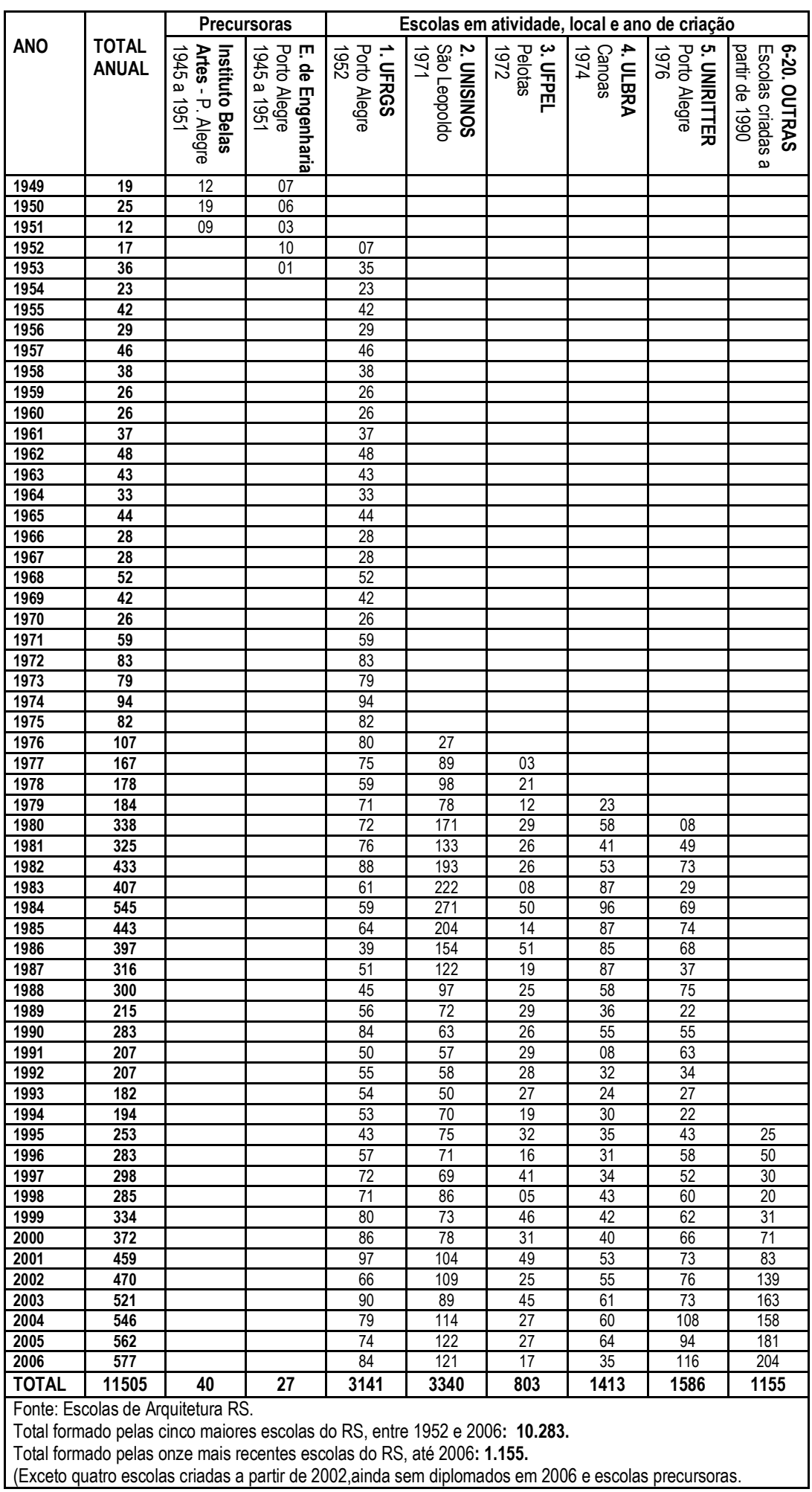


Tabela 3. Escolas de arquitetura RS criadas a partir de 1990, total anual de egressos 1995-2006.

\begin{tabular}{|c|c|c|c|c|c|c|c|c|c|c|c|c|}
\hline \multirow[b]{2}{*}{ ANO } & \multirow[b]{2}{*}{$\begin{array}{l}\text { TOTAL } \\
\text { ANUAL }\end{array}$} & \multicolumn{11}{|c|}{ Escolas em atividade, local e ano de criação } \\
\hline & & 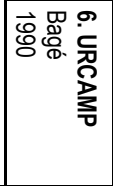 & 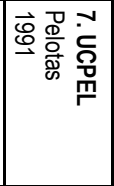 & 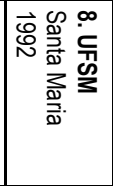 & 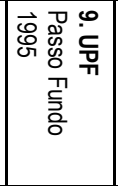 & 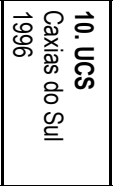 & 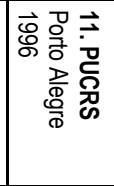 & 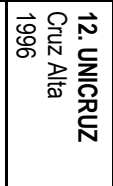 & 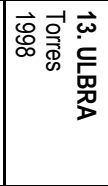 & 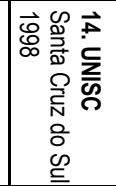 & 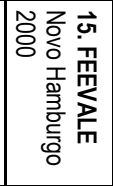 & 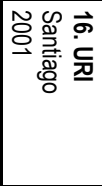 \\
\hline 1995 & 25 & 10 & & & 15 & & & & & & & \\
\hline 1996 & 50 & 10 & 06 & & 34 & & & & & & & \\
\hline 1997 & 30 & 10 & 03 & & 17 & & & & & & & \\
\hline 1998 & 20 & 11 & 08 & 01 & 00 & & & & & & & \\
\hline 1999 & 31 & 12 & 11 & 08 & 00 & & & & & & & \\
\hline 2000 & 71 & 13 & 33 & 25 & 00 & & & & & & & \\
\hline 2001 & 83 & 11 & 26 & 18 & 00 & 05 & 11 & 12 & & & & \\
\hline 2002 & 139 & 07 & 30 & 05 & 23 & 20 & 43 & 11 & & & & \\
\hline 2003 & 163 & 11 & 22 & 26 & 00 & 26 & 57 & 15 & & 06 & & \\
\hline 2004 & 158 & 17 & 22 & 24 & 00 & 21 & 51 & 05 & 08 & 10 & & \\
\hline 2005 & 181 & 06 & 26 & 13 & 00 & 50 & 45 & 05 & 16 & 13 & & 07 \\
\hline 2006 & 204 & 08 & 18 & 05 & 00 & 39 & 54 & 13 & 21 & 21 & 06 & 19 \\
\hline TOTAL & 1155 & 126 & 205 & 125 & 89 & 161 & 261 & 61 & 45 & 50 & 6 & 26 \\
\hline
\end{tabular}

As escolas que respondem pelo número mais significativo de formados ainda estão no conjunto formado pela UFRGS e pelas demais criadas na década de 1970, com destaque para a contribuição da UNISINOS e da ULBRA-Canoas em seus primeiros anos de existência. A principal explicação para os números então atingidos, que nunca mais foram superados por essas últimas, pode estar na posição geográfica de ambas; estas teriam atendido a demandas educacionais da metade norte do Estado, num primeiro momento, atração diminuída à medida que novos cursos foram sendo implantados naquelas regiões. Nos últimos anos, percebe-se um novo incremento no número anual de diplomados pela UNISINOS, a consolidação e a ascensão do curso da UNIRITTER e, ainda, a emergência dos demais cursos criados depois de 1990. Na Figura 4, podem-se visualizar as diferenças na contribuição individual de cada uma dessas maiores escolas, a partir de 1975. A Figura 5, a seguir, compara os números absolutos de diplomados anuais pelas redes pública e privada, e destaca a estabilidade no ritmo formativo da rede pública, o aporte significativo da rede privada instalada nos anos 1970 e o rápido incremento no número de diplomados nas escolas criadas a partir da nova LDB de 1996: 


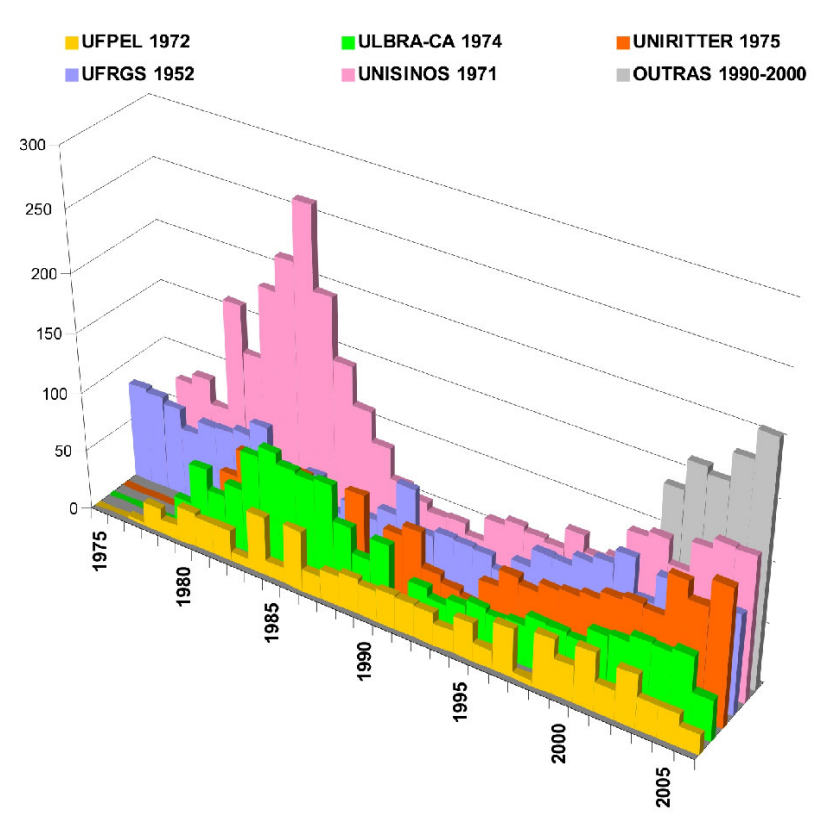

Figura 4. Escolas de arquitetura RS, total de egressos das cinco maiores, 1975-2006.

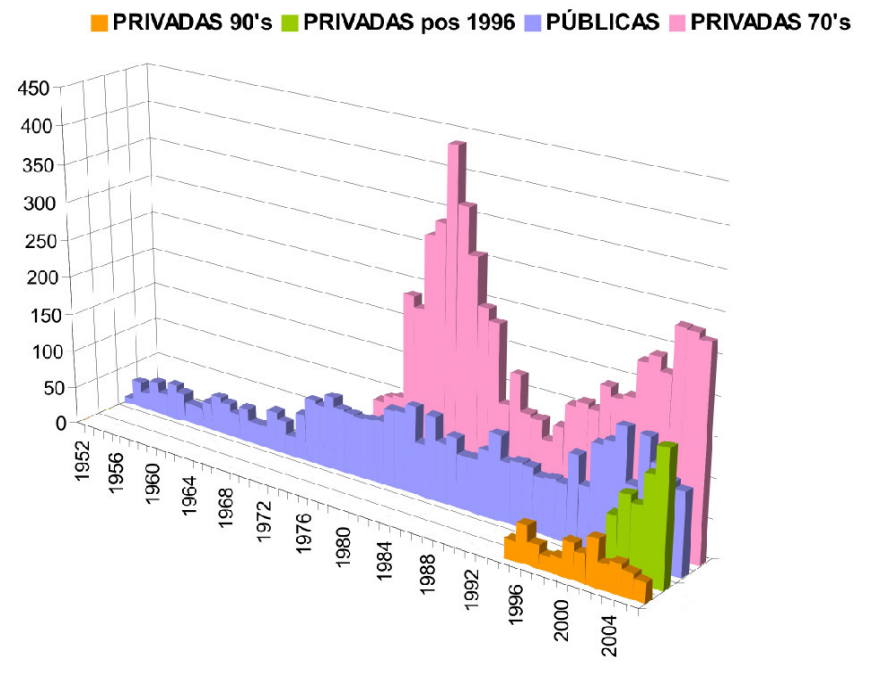

Figura 5. Escolas de arquitetura RS, total de egressos redes pública-privada, 1952-2006.

\section{Notas sobre a feminização da Arquitetura}

No total histórico de diplomados desde 1949, no Rio Grande do Sul, cerca de 56\% correspondem a graduados do sexo feminino. Uma contagem dos profissionais cadastrados em 2003 no Instituto de Arquitetos do Brasil, Departamento do Rio Grande do Sul, realizada por Salvatori (2006), computou 7.278 arquitetos, identificando que 3.188 eram homens $(43,8 \%)$ e 4.058, mulheres (55,8\%), proporções bastante semelhantes ao cômputo total das escolas. A evidência da feminização da atividade necessita de um olhar 
mais detalhado, fora dos objetivos do presente estudo, que se limitará a apontar algumas constatações. Entretanto, registramos que essa parece ser uma ocorrência generalizada no mundo ocidental. Segundo Monedero (2003), isso acontece no ensino europeu, no qual não só as estudantes representam atualmente a maioria das matrículas universitárias, como também os cursos de Arquitetura têm sido escolhidos preferencialmente por uma maioria de mulheres. No Brasil, o fenômeno foi detectado por Durand (1989), que mostra o crescimento da presença feminina na Arquitetura e nas Artes Visuais, em geral, entre 1950 e 1980. Para o autor, o fenômeno seria a evidência da super-escolarização de segmentos sociais que têm a geração anterior em ocupações ou ramos de ensino seguros economicamente ou, ainda, que já colocaram seu contingente masculino da seguinte geração na mesma posição. Ou seja, às mulheres, principalmente as caçulas da mesma geração, caberia maior liberdade de opção.

Esse comportamento foi se configurando ao longo do período, pois a perspectiva era totalmente inversa inicialmente. Em 1949, ano da primeira graduação de estudantes de Arquitetura no estado, somente um dos 19 diplomados era mulher. Aos poucos, a participação feminina foi crescendo até que, em 1973, inverteu-se a predominância de gênero. Considerando individualmente cada uma das maiores escolas do Estado, com exceção da UNIRITTER, que não informou o sexo dos diplomados, verificamos outras peculiaridades no desenvolvimento da tendência.

O curso da UFRGS, de 1952, apesar de ter experimentado primeiro esse fenômeno, ainda computava, em 2006, um total de egressos homens proporcionalmente maior, representando $51,7 \%$ do total de formados por aquela instituição. Caracterizado como o mais antigo, formou um grande contingente masculino em seus primeiros vinte anos, situação que se modificou gradativamente. Em 1973, no que pode ter sido o primeiro reflexo do aumento de vagas proporcionado pela Reforma Universitária de 1969, a proporção de mulheres se elevou, superando ligeiramente a marca dos 50\%. Até 1998, essa instituição formou uma média anual de $45 \%$ de homens, proporção que baixou mais um pouco, e se tornou estável, em torno de $38 \%$ atualmente. Isso pode levar à previsão de que, dentro de pouco tempo, sua estatística histórica de predomínio masculino será superada.

Na UNISINOS, cujo curso tem início em 1971, observa-se que havia equilíbrio entre graduados homens e mulheres, inicialmente. O curso de Arquitetura passou a formar uma média de 40\% homens a partir de 1992 e, depois disso, vem mantendo a proporcionalidade média aproximada de 30\% e 70\% entre diplomados homens e mulheres, respectivamente.

O curso de Arquitetura da UFPEL, de 1972, graduou um grande número de homens em sua primeira turma, cerca de $65 \%$ sobre o total daquele ano. Imediatamente após, passou a formar $40 \%$ em média, até 1996. Nesse ano, a proporção baixaria ainda mais, estabilizando-se em torno de 35\% de diplomados homens a cada ano, aproximadamente.

Um caso atípico é o do curso da ULBRA-Canoas, instituído em 1974. Mesmo não fugindo à regra geral de feminização gradativa, parece experimentá-la de forma mais atenuada. Como a UFRGS, ainda contabiliza um total histórico de egressos homens maior, de 53,0\%. Ao longo do tempo, porém, parece ter mantido atrativos para a clientela masculina, tendo formado cerca 60\% homens, anualmente, por quatorze anos, proporção que, depois de 1993, tem se mantido ao redor de 40\%, e é superior à média das demais escolas. 
A resposta pode estar relacionada à peculiaridade de o curso de Arquitetura ser desenvolvido, exclusivamente, no período noturno.

O comportamento histórico da proporcionalidade entre gêneros para arquitetos formados nas escolas do Rio Grande do Sul pode ser visualizado na Figura $6 a$, enquanto as peculiaridades das quatro maiores escolas podem ser verificadas na Figura 6b. Os gráficos não incluem as contribuições de UNIRITTER e da UPF, que não informaram o sexo de seus egressos.

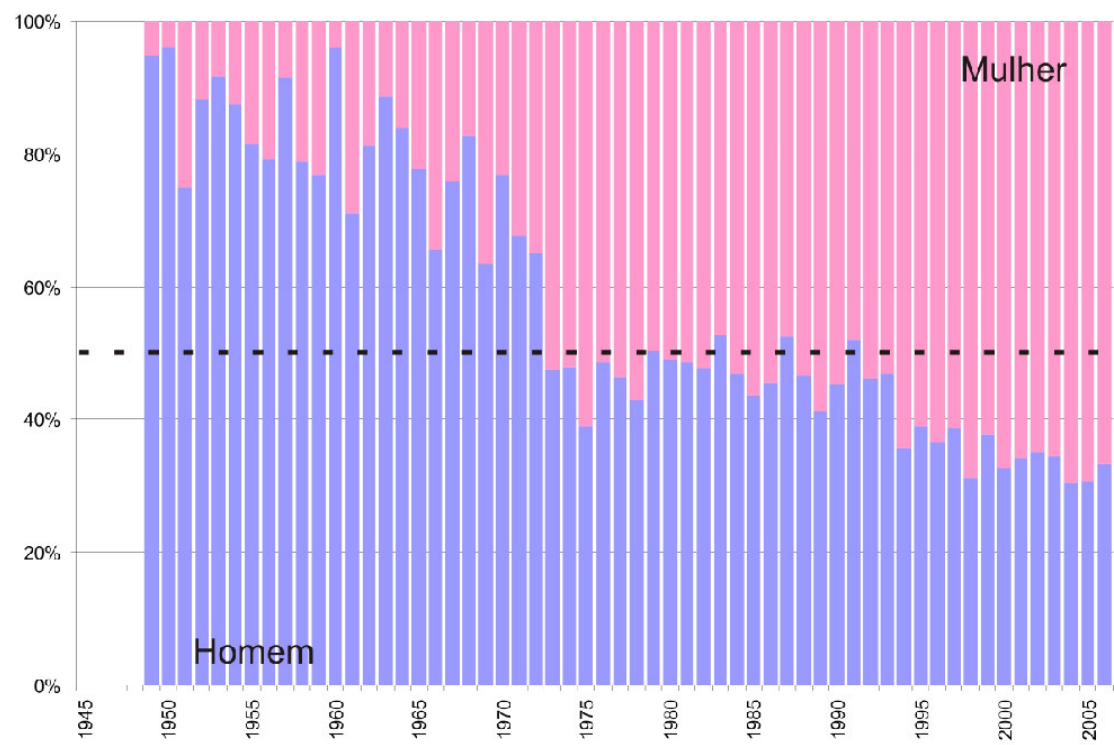

Figura 6a. Arquitetos diplomados no RS, composição por gênero, 1949 a 2006. 


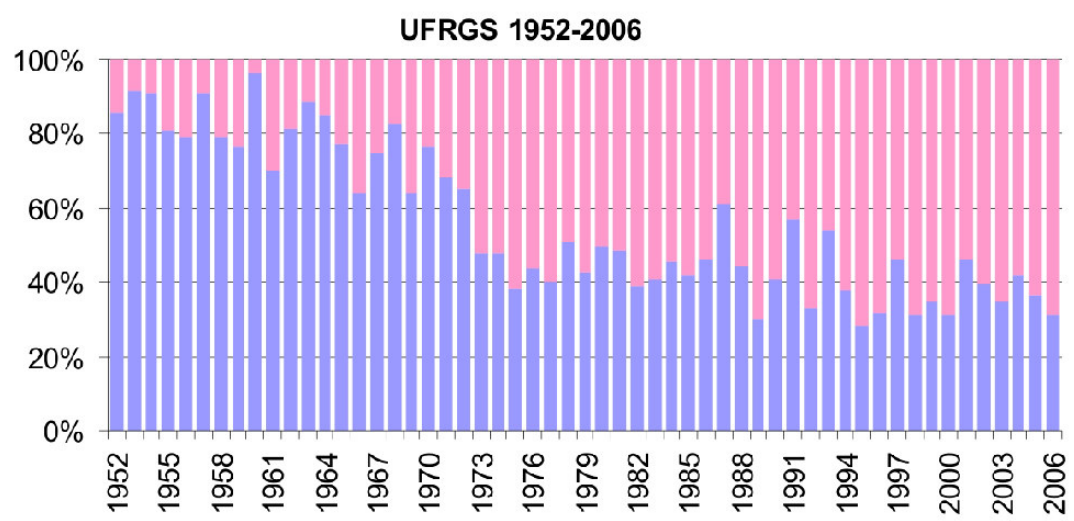

UNISINOS 1976-2006
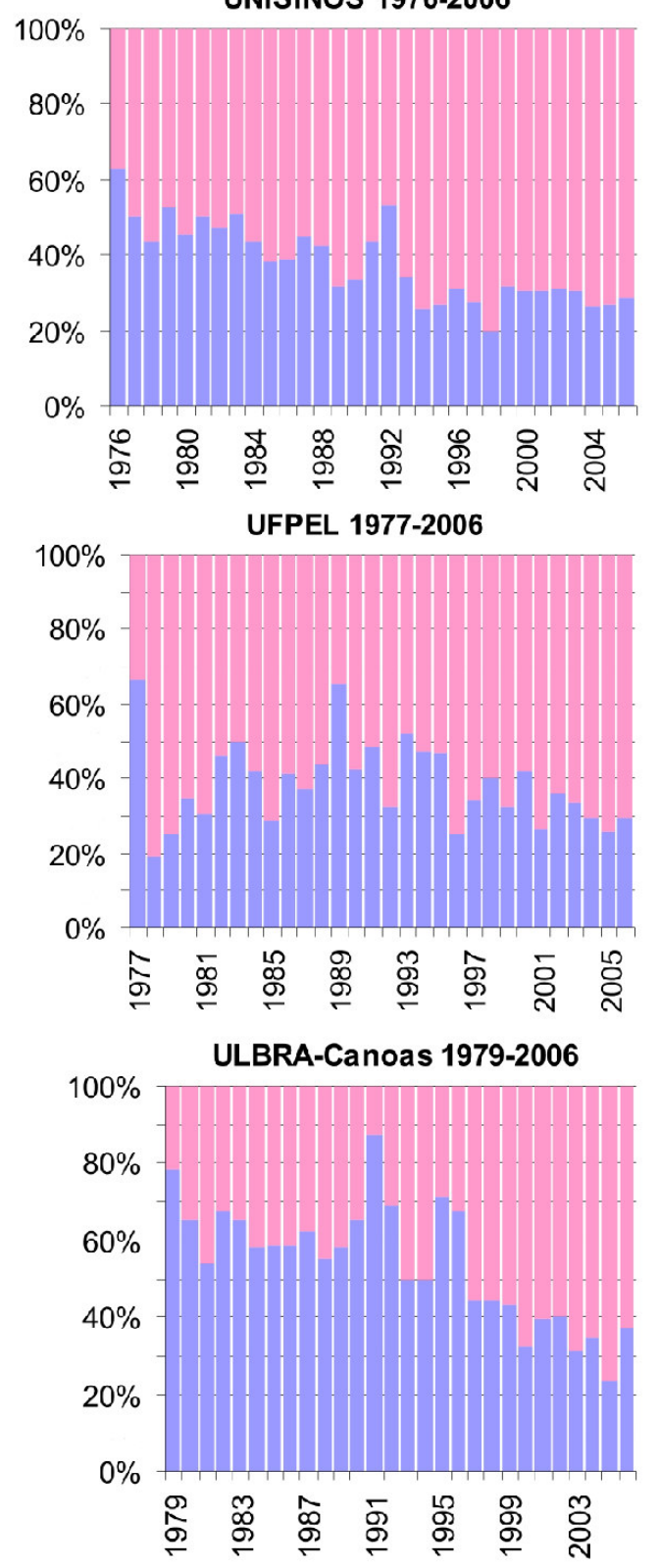

Figura 6b. Arquitetos diplomados no RS, composição por gênero nas maiores escolas, 1952-2006. 


\section{Arquitetos em atividade no RS}

O Rio Grande do Sul é o quinto estado mais populoso do Brasil, com 10.582.840 habitantes (estimativa IBGE, 2007); permanece atrás somente de São Paulo, Minas Gerais, Rio de Janeiro e Bahia. Situado na região Sul, de bom desempenho nos quesitos renda e escolaridade segundo o PNAD 2006 (ver Tabela 1), apresenta um índice ainda superior em escolaridade média, com 7,0 anos de estudo na faixa populacional de 25 anos e mais. Na região metropolitana de Porto Alegre, essa média é de 8,0 anos, só abaixo da região metropolitana do Rio de Janeiro (RJ), com 8,1 anos, e do Distrito Federal (DF), com 8,9. A média do total de rendimentos mensais per capita é $\mathrm{R} \$ 902,10$ no estado, portanto, menor que o índice regional. Os maiores rendimentos estão concentrados na região dos arredores de Porto Alegre, que apresenta uma média de $\mathrm{R} \$$ $1.120,10$, somente menor que a da região metropolitana de São Paulo e a do Distrito Federal.

A região Sul apresenta os maiores índices relativos à proporcionalidade de arquitetos e escolas, em relação às demais regiões brasileiras. Mas o maior número de arquitetos e escolas está no estado do Rio Grande do Sul, que abriga cerca de $50 \%$ do total de arquitetos e $43 \%$ das escolas de Arquitetura da região Sul. Segundo o Conselho Federal de Engenharia, Arquitetura e Agronomia - CONFEA, o estado abrigaria, atualmente, 8.107 arquitetos em atividade - considerados assim os registrados regularmente no sistema -, apresentando 0,766 arq/1.000 hab - índice que o colocaria na escala de Portugal, que tem 0,796 arq/1.000 hab. A proporcionalidade de escolas de Arquitetura é de 1,889 esc/1 milhão hab, enquanto a média brasileira se situa em 1,000 (ver Tabela 1 ).

Mas, diferentemente da cifra fornecida pelo CONFEA, a Câmara Especializada de Arquitetura do CREA-RS registrava a presença regular de 9.417 arquitetos em seu sistema após o recadastramento geral de 2007 (dados de maio de 2008, quando o processo foi encerrado). Ou seja, esta proporcionalidade poderia chegar a 0,890 arq/1.000 hab no Estado, mais que o dobro da média brasileira. Outro dado importante que precisa ser atualizado, tendo em vista o surgimento de Cursos em cidades do interior do Estado, é o da distribuição geográfica desses arquitetos. Em 2002, segundo Salvatori (2006), cerca de 60\% dos arquitetos gaúchos estavam estabelecidos em Porto Alegre, o que faz a relação subir a 2,873 arq/1.000 hab. Essa cifra superava a posição recorde do Japão deste mesmo ano (2,292 arq/1.000 hab), enquanto os demais municípios gaúchos contavam com 0,299 arq/1.000 hab, índice abaixo do apresentado pela Bolívia, por exemplo. Esses dados comparativos de proporcionalidade são os da União Internacional dos Auquitetos UIA, de 2002, segundo Monedero (2003).

Também em 2002, de acordo com Salvatori (2006), estavam registrados no CREA-RS 6.646 arquitetos, e a população gaúcha estimada pela IBGE era de 10.274.197 habitantes. O índice de arquitetos em atividade no estado calculava-se, então, em 0,646 arq/1.000 hab. Tomando-se o número de 9.417 arquitetos registrados, em maio de 2008, tal como informado pelo CREA-RS, num espaço de tempo de apenas cinco anos, verificase um incremento de $42 \%$ no número total de arquitetos em atividade e $37 \%$ de aumento no índice de proporcionalidade arquitetos/habitantes (de 0,646 para 0,890). O aumento no número absoluto de arquitetos representou um crescimento aproximado de 6,5\% ao ano, de 2002 a 2007, enquanto a taxa de crescimento demográfico anual do Estado foi de 1,22\% no intervalo censitário de 1991 a 2000. 
A Figura 7, a seguir, compara a série histórica de egressos das escolas de Arquitetura do estado do Rio Grande do Sul com os novos registros de arquitetos no sistema CREA-RS, nos mesmos anos, conforme dados informados por sua Câmara Especializada de Arquitetura.

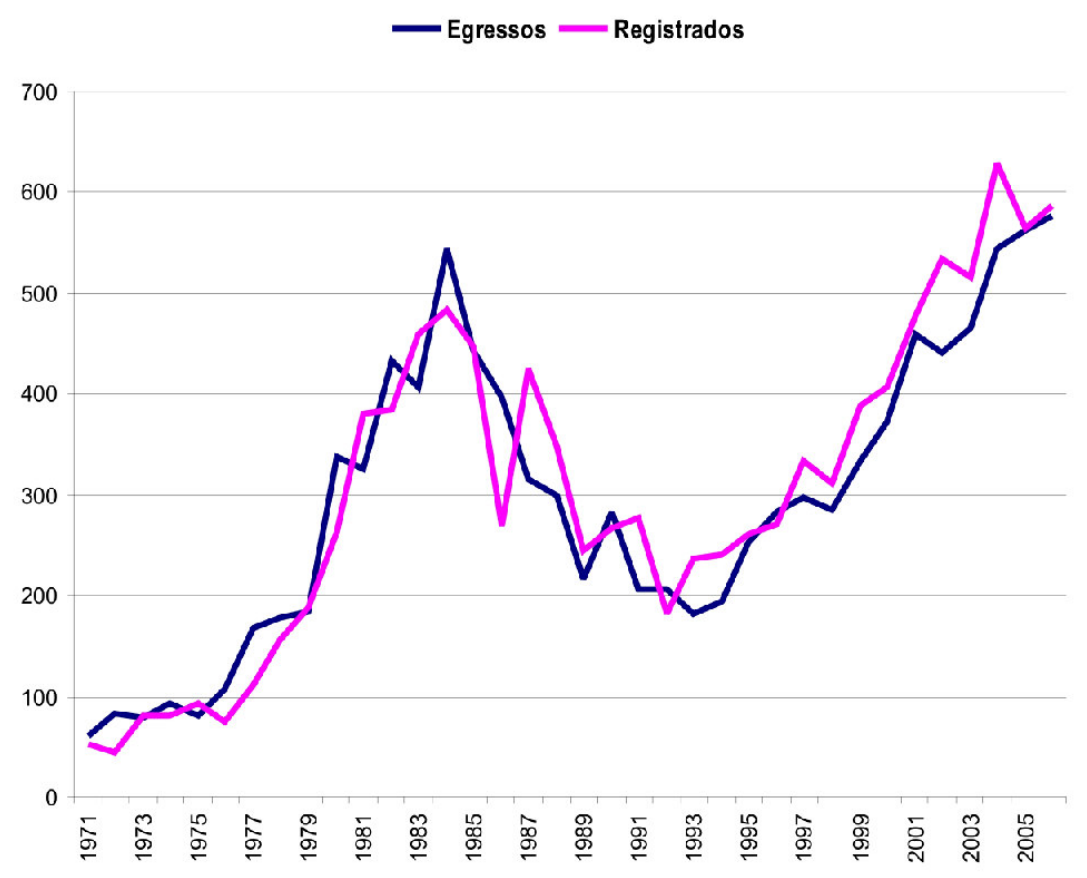

Figura 7. Arquitetos egressos RS x novos registros CREA-RS, 1971-2006.

Para realizar a comparação, tomaram-se os últimos trinta e cinco anos, de 1971 e 2006, abrangendo um universo de profissionais que pudessem, ainda, estar no mercado de trabalho. Nesse intervalo, as escolas gaúchas diplomaram 10.701 novos arquitetos, já o sistema CREA-RS registrou 11.067 novos profissionais. Encontram-se atualmente 9.417 profissionais com registros ativos no estado; ou seja, $15 \%$ dos profissionais registrados no período abandonaram a atividade, seja por aposentadoria ou outros motivos.

Como se pode constatar no desenvolvimento da curva, até início dos anos 1980, havia, geralmente, um número menor de registros em relação aos egressos do mesmo ano; como esse valor aparece compensado no intervalo seguinte, leva a crer que o registro profissional acabava sendo feito num futuro muito próximo. Verifica-se uma maior defasagem entre diplomação e registro a partir de 1984 , em que essa compensação imediata não é tão evidente, talvez por ser um período de instabilidade e de sucessivas crises econômicas. Há um pico no número de registros em 1987, claramente relacionado à época de otimismo econômico e ao financiamento fácil do denominado "Plano Cruzado", de efêmera eficácia no saneamento da economia brasileira. Mas, a partir de princípios dos anos 1990, o número de egressos permanece, de modo geral, abaixo da linha de registro, até 2005-2006, quando ambos os valores voltam a coincidir. 
A constatação de um número de arquitetos registrados superior ao de egressos dos cursos locais é, porém, insuficiente para diagnosticar um comportamento otimista do mercado de trabalho e concluir pela completa assimilação dos profissionais formados por escolas gaúchas e pela afluência de profissionais de outras origens ao estado. A correta interpretação desses dados demandará o aporte complementar de outras pesquisas. Deve ser apurado, por exemplo, se o número total de novos registros inclui, na verdade, profissionais que circulam sazonalmente no mercado de trabalho, alternando ingressos e saídas do sistema CREA.

\section{Ensino e profissão}

Além dos aspectos estritamente econômicos, deve-se reconhecer que a instituição da Arquitetura no Brasil, como campo profissional e como campo de conhecimento, foi um processo que resultou da composição de diferentes circunstâncias, relativamente à sua época e ao contexto e à forma como os arquitetos vêm se posicionando a cada etapa. É possível reconhecer, inicialmente, o grande esforço empreendido desde o interior da categoria para obtenção de visibilidade social, assim que the foram dadas as condições para seu desenvolvimento a princípios do século XX. Nesse sentido, a introdução quase simultânea da Arquitetura Moderna no país, como um corpo doutrinário suficientemente amplo e coerente que relacionava o campo profissional local às vanguardas européias, forneceu os elementos identitários que permitiram a construção de certa hegemonia, pelo menos até meados dos anos 1970.

A criação da Faculdade Nacional de Arquitetura - FNA, no Rio de Janeiro, em 1945, marcaria a substituição dos antigos catedráticos da Escola Nacional de Belas Artes por professores plenamente identificados com a Arquitetura Moderna, e que formaram, por sua vez, os novos mestres que disseminaram os mesmos valores em outras escolas do país. O próprio currículo da FNA, que incluía a escala urbano-territorial no âmbito de atuação do arquiteto, ampliando os limites epistemológicos da disciplina, serviu de modelo a muitos cursos implantados desde então. Mas, apesar de incluir um maior número de professores arquitetos em seus quadros, seus conteúdos curriculares e procedimentos pedagógicos ainda permaneciam bastante parecidos com os do curso de origem. Outro modelo de formação de arquitetos era o das Escolas Politécnicas, adotado por cursos paulistas e pelos cursos de Arquitetura das escolas de Engenharia do País.

Na seguinte década, a de 1950, a Arquitetura brasileira havia obtido amplo reconhecimento internacional e caminhava para sua realização emblemática, representada pela construção de Brasília. A categoria profissional encontrava-se fortalecida e promoveu discussões em todo o território nacional, mediante a realização de três Encontros Nacionais de Arquitetos, Estudantes e Professores de Arquitetura, em 1958, 1959 e 1962. O objetivo desses encontros foi definir uma identidade profissional inconfundível com o campo das Artes e das Engenharias, que deveria ser forjada por intermédio de uma formação específica.

Baseado nas recomendações desses encontros, o Conselho Federal de Educação aprovou, em 1962, o primeiro Currículo Mínimo de Arquitetura (Parecer CFE 336/1962), que instituiu um conjunto de conteúdos 
obrigatórios aos Programas de Ensino de todas as escolas do país. Abandonava-se a era dos modelos curriculares, para ingressar em uma etapa de autonomia em que as escolas poderiam desenvolver suas peculiaridades e organizar-se livremente, respeitadas as disposições do CFE. Uma dessas era a destinação de metade do tempo mínimo de formação (3.600 horas-aula, distribuídas em dez semestres letivos) às atividades de projeto, definido, nessa época,, como o produto típico da atividade do arquiteto.

A partir de uma primeira etapa de afirmação profissional, em que coincidiram objetivos da categoria dos arquitetos e objetivos desenvolvimentistas dos governos instituídos, ocorreu uma segunda, de definição do perfil profissional, que estimulou diversas experiências na implementação das disposições do Currículo Mínimo de 1962. Mas, logo, as escolas se depararam com a Reforma Universitária, promovida pelos Governos militares entre 1969 e 1972, que substituiu o paradigma clássico de Universidade do conhecimento pelo de Universidade funcional, voltada ao mercado de trabalho, de acordo com Chauí (in Rheingantz, 2003). Com o novo Currículo Mínimo promulgado (Parecer CFE 384/1969), o ciclo profissional do curso de Arquitetura foi reduzido, efetivamente, a três anos, e interrompeu a maturação do projeto pedagógico específico em curso.

A década de 1970 apresentou diversos fatores que contribuíram para a perda de hegemonia da Arquitetura Moderna, para a fragmentação do campo profissional e para o progressivo distanciamento entre as instâncias acadêmicas e as entidades de representação profissional. Entre eles: a ambigüidade da situação sociopolítica e suas repercussões nas escolas e no mercado de trabalho, bem como a complexidade crescente do último, já comentados; o surgimento de instituições privadas de ensino, orientadas segundo os novos paradigmas, a partir do não atendimento do crescimento da demanda educacional pelas instituições públicas existentes; a organização de instâncias dedicadas exclusivamente às questões educacionais, como a Associação Brasileira de Escolas de Arquitetura (ABEA), em 1973 (transformada em Associação Brasileira de Ensino de Arquitetura em 1985), que tentaram continuamente resgatar alguns princípios da proposta do Currículo Mínimo de Arquitetura de 1962, sem êxito. Diversas circunstâncias, entre 1969 e 1994 , retardaram o aperfeiçoamento do Currículo Mínimo, apesar das discussões promovidas pela ABEA e de, pelo menos, duas tentativas de reformulá-lo, incluindo conteúdos como a questão ambiental e patrimonial, a integração de novas tecnologias informatizadas, a multidisciplinaridade, a implantação de laboratórios e a integração da Pós-Graduação ao ensino. A questão foi enfrentada diferentemente pelas diversas escolas de Arquitetura e resultou numa grande diversidade de propostas, para não dizer na dissolução do conceito de perfil profissional que esteve na origem da instituição do Currículo Mínimo.

No caso da Faculdade de Arquitetura da UFRGS, houve o desejo expresso de ampliar as competências profissionais para além da atividade de projeto. Uma alteração curricular de 1982 revalorizava as disciplinas técnicas, propondo um novo perfil profissional: o do arquiteto capaz de atender ao projeto e à construção, bastante de acordo com a perspectiva tecnocrática da época e das oportunidades de trabalho concretas criadas pelos Planos Nacionais de Desenvolvimento. Na impossibilidade de alterar a estruturação dos cursos superiores, que possuíam um ciclo básico de dois anos, a partir da Reforma Universitária de 1969, a solução encontrada foi de aumento do número de disciplinas especializadas e de conteúdos complementares. Isso 
resultou em uma carga horária total de 4.935 horas, no lugar das 3.600 obrigatórias do Currículo Mínimo legal.

No âmbito estatal, o Governo Federal implantou alguns instrumentos de aferição de resultados, destinados à regulação do crescente mercado educacional e que, nos anos 80 , levaram à busca de novos patamares de competência nas carreiras docentes. O estabelecimento de planos de carreira universitária deu lugar à profissionalização acadêmica; no caso específico da Arquitetura, isso significou afastar professores de reconhecida prática profissional, substituindo-os por outros com trajetórias tipicamente intelectuais. Um pouco mais tarde, já na década de 90, ao mesmo tempo em que se facilitava o desenvolvimento de instituições de ensino superior privadas e de interesse empresarial (veja-se repercussão dessa política na Figura 3), se implantaram instrumentos de aferição da produtividade docente, dando-se lugar à Universidade dos resultados. Ou seja, as sucessivas crises econômicas da década de 80, que podem ter repercutido nos planos de ascensão de certos segmentos sociais e afastado estudantes de áreas comprometidas como a Arquitetura (veja-se a diminuição efetiva de diplomados conseguintes a esta época na mesma Figura 3), se desenvolveram simultaneamente a um incremento na qualificação formal do corpo docente dos cursos de Arquitetura do país, processo que se acentuou nos anos 1990.

Na Faculdade de Arquitetura da UFRGS, esse aumento no grau de exigência na formação dos docentes coincidiu com o ingresso de jovens professores, que realizaram, em 1985, um Encontro sobre o Ensino de Projeto Arquitetônico, cujos extratos foram publicados por Comas (1986). As discussões expressavam inquietações referentes à falta de conexão entre as propostas curriculares e o resultado do processo educativo, e ao silêncio da Arquitetura Moderna relativamente aos aspectos metodológicos do projeto, contraditoriamente produto de uma operação lógica, por um lado, e da intuição genial, por outro. Um dos resultados mais relevantes desse encontro e das experiências levadas a efeito nas disciplinas de projeto, a partir de então, foi a proposta de construção de uma disciplina projetual estruturada, na qual técnicas e procedimentos estivessem identificados e fundamentados em um corpo de conhecimentos instrumentais, ampliados pela pesquisa continuada e que incorporassem, por sua vez, a noção de tradição arquitetônica. Pode-se dizer que esse fenômeno, apesar de localizado, foi representativo de outros processos em desenvolvimento no país, que redundaram, em 1994, na proposta das "Diretrizes Curriculares" (Portaria MEC 1770/1994), as quais substituíram a figura dos Currículos Mínimos vigentes desde 1962.

Uma característica destas Diretrizes Curriculares de 1994 foi, na mesma ambição de construção de um corpo disciplinar autônomo e universal, a busca de aproximação aos padrões internacionais, precocemente às preocupações que a UIA e a UNESCO manifestariam na Charter of Architectural Education de 1996, às recomendações da Conferência Mundial da Educação Superior de Paris de 1998 e à criação do Mercado Comum do Cone Sul (Mercosul), em 1997. As Diretrizes Curriculares marcariam o retorno das instituições profissionais representativas, por meio do CONFEA e da Federação Nacional dos Arquitetos (FNA), à discussão das questões de ensino de Arquitetura no Brasil. Estão, ainda, relacionadas a uma época em que se substitui a regulação estatal pela de mercado, liberalização que patrocinou o grande crescimento de escolas, especialmente após sua promulgação (ver Figura 3). Contraditoriamente, mas, certamente, devido à participação de entidades com interesses corporativos, foi incluído conteúdo que definiu o perfil 
profissional com base nas competências no mercado de trabalho. Essa tentativa de regular a oferta fica mais clara na nova versão publicada em 2006 (Diretrizes Curriculares Nacionais, Resolução CES-CNE 6/2006), nas quais se especificam competências profissionais mínimas, que deverão estar, agora, explicitamente contempladas pelos projetos pedagógicos dos cursos.

Compreende-se que a hegemonia pretendida e, até certo ponto, alcançada pela Arquitetura Moderna no Brasil, foi efetiva em um contexto em que o número de escolas era reduzido, o campo profissional estava limitado às obras de caráter excepcional e a categoria profissional era proveniente de estratos sociais identificados com suas realizações, não havendo, aparentemente, problemas de colocação profissional. Essa hegemonia, fundada no pertencimento a certa elite intelectual, sofreu solução de continuidade a partir do crescimento geométrico do número de cursos e, por conseqüência, do total de arquitetos diplomados, da diversificação das demandas e dos mercados e do aumento da competição entre profissionais. Compreendese, ainda, que a construção de uma identidade baseada na continuidade da tradição arquitetônica e em uma definição disciplinar claramente delineada tem sua funcionalidade nesse contexto de transformações, que não demandou a continuidade do papel social da Arquitetura, substituída por sua adequação às condições produtivas existentes.

\section{A necessidade de saber mais sobre ensino e profissão}

Dados recentemente divulgados por Serapião (2008), relativos ao Prêmio Opera Prima, que há vinte anos vem destacando projetos de graduação das escolas de Arquitetura nacionais, dão conta de que cerca de $25 \%$ dos premiados estão fora da área ou em áreas correlatas. Dos que continuam na área da Arquitetura, $21,8 \%$ trabalham em escritórios de terceiros, e 48,43\% possuem escritório próprio. Mas quase metade desses últimos concilia a atividade privada com a docência - importante campo de trabalho para arquitetos, atualmente - e, outra parte significativa, com atividades no setor público, com possibilidade, ainda, de prestar serviços para terceiros. O autor fala sobre jovens arquitetos que inauguraram a prática profissional em uma situação de distinguida excepcionalidade. Há todo um campo a ser desvendado relativamente à massa de arquitetos que saem, atualmente, das escolas de Arquitetura e que traçam suas estratégias profissionais a partir de competências pessoais médias.

Para uma melhor aproximação a essa questão, seria necessário verificar em que medida o registro no sistema CREA corresponde ao efetivo exercício profissional, cruzando dados numéricos com outros dados qualitativos. conhecer a quantidade, natureza e a dimensão dos serviços constantes das Anotações de Responsabilidade Técnica emitidas pelos arquitetos e, ainda, o número e a natureza dos processos administrativos e de infração que tramitam nas Câmaras Especializadas de Arquitetura, em cada Estado. Esta é uma pesquisa que pode já estar em andamento dentro do CONFEA, de acordo com informações prestadas pela Coordenadoria de Câmaras Especializadas de Arquitetura da mesma Instituição, em agosto de 2008. Seria de grande utilidade levantar, ainda, informações referentes à naturalidade e à instituição de origem dos profissionais registrados, para que se pudesse estabelecer o quadro da mobilidade dos arquitetos. 
Além dos dados que possam ser levantados dentro do sistema CREA-CONFEA, conhecer o segmento social de origem do ingressante dos cursos de arquitetura, ou seja, a escolaridade e ocupação de pais e avós, mesmo de forma amostral, poderia introduzir novas variáveis para compreender o desenvolvimento da demanda educacional. Há indícios de que o campo da arquitetura recebe, preferencialmente, candidatos de dois agregados sociais: os relacionados, mesmo que tangencialmente, com a construção civil e a ocupação do território, e os que apresentam antecedentes no domínio estético.

Por outro lado, as pesquisas realizadas pelos próprios cursos, acompanhando a evolução das realizações, atividades e vínculos de seus egressos, poderão aportar, igualmente, dados de grande interesse para um diagnóstico mais preciso da adequação das propostas pedagógicas à realidade da prática profissional. Dentro de um contexto como o do Rio Grande do Sul, que formou arquitetos numa taxa mais de cinco vezes superior à de seu próprio crescimento populacional nos últimos cinco anos e que receberá, proximamente, a contribuição de mais quatro novas escolas, a qualidade dos cursos será a medida de sua sobrevivência no mercado da educação e da adequada inserção dos profissionais no mercado de trabalho.

\section{Agradecimentos}

Este estudo é o desdobramento de diversas pesquisas sobre ensino na Faculdade de Arquitetura da UFRGS, realizadas a partir de 1997, que culminaram com uma tese focada na evolução institucional durante o período de vigência dos Currículos Mínimos no Brasil (1962 a 1994). A coleta de dados sobre os demais cursos gaúchos demandou cerca de dois anos, e não teria sido possível sem a receptividade e positiva colaboração encontrada em todas as escolas de Arquitetura do Rio Grande do Sul, seja na figura de seus Diretores e Coordenadores de Curso e, ainda, de alguns professores "embaixadores" e de seu pessoal técnico-administrativo. Também se contou com o decisivo aporte de informações do sistema CREA-CONFEA e, especialmente, da Câmara Especializada de Arquitetura do CREA-RS. A todos, meu grande agradecimento, esperando que o produto obtido possa ser útil ao conhecimento do ensino e da profissão de Arquitetura. E, muito especialmente, agradeço ao Prof. Dr. José Carlos Garcia Durand, por sua leitura atenta e crítica, que acrescentou novas perspectivas ao encaminhamento do tema.

\section{Referências}

ABEA - ASSOCIAÇÃO BRASILEIRA DE ENSINO DE ARQUITETURA. 2003. O panorama do ensino de Arquitetura e Urbanismo no Brasil. Rio de Janeiro, ABEA. [CD-ROM].

BARRETO, S.M. da C. 1983. Maestro sem orquestra: um estudo da ideologia do arquiteto no Brasil (18201950). Recife, PE. Tese de doutorado. Universidade Federal de Pernambuco- UFP, 207 p.

COMAS, C.E. (org.). 1986. Projeto Arquitetônico: disciplina em crise, disciplina em renovação. São Paulo, Ed. Projeto, 94 p. 
DURAND, J.C.G. 1989. Arte, privilégio e distinção: artes plásticas, arquitetura e classe dirigente no Brasil, 1855/1985. São Paulo, Ed. Perspectiva, 334 p.

FEATHERSTONE, M. 1995. Cultura de consumo e pós-modernidade. São Paulo, Nobel, 223 p.

FIORE, R.H. 1992. Arquitetura moderna e ensino de arquitetura: os cursos em Porto Alegre de 1945 a 1951. Porto Alegre, RS. Dissertação de mestrado. Pontifícia Universidade Católica do Rio Grande do Sul PUCRS, $420 \mathrm{p}$.

GRAEFF, E. A. 1995. A arte e a técnica na formação do arquiteto. São Paulo, Fundação Vilanova ArtigasStudio Nobel, 142 p.

GUERRA, A. 2001. A opinião dos críticos. Projeto Design, 251:42-43.

IANNI, O. 1971. Estado e planejamento econômico no Brasil, 1930-1970. Río de Janeiro, Civilização Brasileira, $316 \mathrm{p}$.

IBGE - INSTITUTO BRASILEIRO DE GEOGRAFIA E ESTATÍstICA. 2001. Sinopse Preliminar do Censo Demográfico 2000. Rio de Janeiro, IBGE, V7, 415 p.

IBGE - INSTITUTO BRASILEIRO DE GEOGRAFIA E ESTATÍSTICA. 2006. Síntese de Indicadores Sociais 2006. Rio de Janeiro, IBGE. Estudos e Pesquisas: Informação Demográfica e Sócio-Econômicas número 19, $317 \mathrm{p}$.

IBGE - INSTITUTO BRASILEIRO DE GEOGRAFIA E ESTATÍSTICA. 2007. Contagem da população 2007. Rio de Janeiro, IBGE, $311 \mathrm{p}$.

MONEDERO, J. 2003. Enseñanza y práctica profesional de la arquitectura en Europa y Estados Unidos: Estudio comparativo sobre la situación en el año 2000: Unión Europea. Barcelona, DEGA-ETSAB, 373 p.

ORSO, P.J. 2001. O surgimento tardio da Universidade Brasileira. EDT-Educação Temática Digital, 3(1):1-13.

PASSAGLIA, L.A. do P. 1991. A influência do movimento da Arquitetura Moderna no Brasil na concepção do desenho e na formação de arquiteto. São Paulo, SP. Dissertação de Mestrado. PG-FAUUSP, 245 p.

RHEINGANTZ, P.A. 2003. Arquitetura da autonomia. In: F. LARA; S. MARQUES (orgs.), Projetar: desafios e conquistas da pesquisa e do ensino em projeto. Rio de Janeiro, Ed. Virtual Científica, 173 p.

RISTOFF, D.; GIOLO, J. 2006. Educação Superior Brasileira, 1991-2004: Rio Grande do Sul. Brasília/DF, Ed. INEP-MEC, $390 \mathrm{p}$.

SALVATORI, E. 2006. De la originalidad a la competencia: la enseñanza de Arquitectura en la UFRGS, Porto Alegre, Brasil - 1962 a 1994. Barcelona, Espanha. Tese de doutorado. DCA-ETSAB-UPC, 244 p. Disponível em: www.tdx.cat/TDX-0427107-101700.

SEGAWA, H. 1999. Arquiteturas no Brasil: 1900-1990. São Paulo, EDUSP, 224 p.

SERAPIÃO, F. 2008. O que aconteceu com os premiados do Opera Prima? Boletim ARCOWEB Acessado em: 09/09/2008, disponível em: www.arcoweb.com.br/especiais/especiais32.asp. 